Research Article

\title{
Liquid Chromatography-Tandem Mass Spectrometry Method for the Determination of Vardenafil and Its Application of Bioequivalence
}

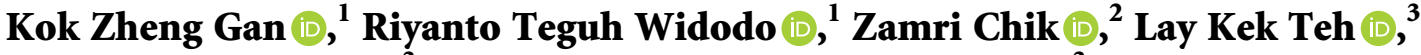 \\ Mohd Salleh Rofiee $\mathbb{D D}^{3},{ }^{3}$ and Mohd Izwan Mohamad Yusof $\mathbb{i D}^{3}$ \\ ${ }^{1}$ Department of Pharmaceutical Technology, Faculty of Pharmacy, University of Malaya, 50603 Kuala Lumpur, Malaysia \\ ${ }^{2}$ University of Malaya Bioequivalence Testing Centre (UBAT), Department of Pharmacology, Faculty of Medicine, \\ University of Malaya, 50603 Kuala Lumpur, Malaysia \\ ${ }^{3}$ Integrative Pharmacogenomics Institute (iPROMISE), Universiti Teknologi MARA, Bandar Puncak Alam 42300, Shah Alam, \\ Selangor, Malaysia \\ Correspondence should be addressed to Riyanto Teguh Widodo; riyanto@ummc.edu.my
}

Received 4 February 2021; Revised 11 March 2021; Accepted 17 March 2021; Published 26 March 2021

Academic Editor: Victoria F. Samanidou

Copyright $\odot 2021$ Kok Zheng Gan et al. This is an open access article distributed under the Creative Commons Attribution License, which permits unrestricted use, distribution, and reproduction in any medium, provided the original work is properly cited.

\begin{abstract}
A simple, rapid, and sensitive method of liquid chromatography-tandem mass spectrometry (LC/MS/MS) method was developed and validated for the determination of vardenafil in rabbit plasma. A simple protein precipitation method with ice-cold acetonitrile was used for plasma extraction. The mass transitions $\mathrm{m} / \mathrm{z} 489 \longrightarrow 151$ and $\mathrm{m} / \mathrm{z} 390 \longrightarrow 169$ were used to measure vardenafil and tadalafil (internal standard), respectively, with a total assay run time of $6 \mathrm{~min}$. The limit of detection was $0.2 \mathrm{ng} / \mathrm{mL}$. The assay was reproducible with intra-assay and interassay precision ranging $1.17 \%-9.17 \%$ and $1.31 \%-5.86 \%$, respectively. There was also good intra-assay and interassay accuracy between $89.3 \%-105.3 \%$ and $94 \%-102 \%$ of the expected value, respectively. The linearity range was $0.5-60 \mathrm{ng} / \mathrm{mL}$ in rabbit plasma $\left(r^{2} \geq 0.99\right)$. The measured AUC from 0 to $24 \mathrm{~h}\left(\mathrm{AUC}_{0-24 t}\right)$ for the test and reference formulations were $174.38 \pm 95.91$ and $176.45 \pm 76.88$, respectively. For the test, $C_{\max }$ and $T_{\max }$ were $75.36 \pm 59.53 \mathrm{ng} / \mathrm{mL}$ and $1.42 \pm 0.19 \mathrm{~h}$, whereas, for the reference, these were $58.22 \pm 36.11 \mathrm{ng} / \mathrm{mL}$ and $2.04 \pm 0.33 \mathrm{~h}$, respectively. The test formulation achieved a slightly lower $\mathrm{AUC}_{0-24 t}$ value $(p>0.05)$, higher $C_{\max }$ values $(p>0.05)$, faster $T_{\max }(p<0.05)$, and almost equal bioavailability compared with the reference formulation.
\end{abstract}

\section{Introduction}

Vardenafil (2-[2-ethoxy-5-(4-ethylpiperazin-1-yl)sulfonylphenyl]-5-methyl-7-propyl-3H-imidazo $[5,1-f][1,2,4]$ triazin-4-one; trihydrate; hydrochloride) is a highly potent and selective phosphodiesterase 5 (PDE5) inhibitor [1]. This is generally well-tolerated in men with erectile dysfunction (ED) with no reports of abnormal color vision at recommended doses (5-20 mg) [2]. Vardenafil was shown to have 4- to 25-fold selectivity toward PDE5 compared with sildenafil and tadalafil, which only demonstrated 10- and 5fold selectivity, respectively $[1,2]$. High-fat meals were observed to reduce vardenafil absorption if taken orally with an $18 \%-50 \%$ reduction in maximum concentration $\left(C_{\max }\right)$ [3]. Vardenafil is highly bound to plasma protein (95\%). The mean half-life $\left(t_{1 / 2}\right)$ of vardenafil ranges from 3.94 to $4.79 \mathrm{~h}$ [2]. It is extensively metabolized in the liver mainly by cytochrome P450 (CYP) 3A4 and a smaller portion by CYP3A5 and CYP2C isoforms [3]. Vardenafil film-coated tablets undergo extensive first-pass metabolism, and their absolute bioavailability is approximately $15 \%$ [4].

Formulating vardenafil in an orodispersible tablet dosage form can bypass the first-pass metabolism in the liver and can be taken even after a meal, thus improving patient 
satisfaction [5-7]. An integrated analysis concluded that vardenafil orodispersible tablets significantly improve erectile function in men with ED, regardless of baseline ED severity, age, or underlying conditions [8]. However, the presently marketed vardenafil orodispersible tablet takes a longer time to reach maximum concentration $\left(T_{\max }\right)[5,9]$. Inappropriate use of excipients in orodispersible formulations causes the drug to mainly be absorbed via the gastrointestinal route rather than the oral transmucosal route [5]. Thus, the current orodispersible formulation should have a faster onset of action by reducing $T_{\max }$. Additionally, the newly optimized orodispersible formulation must also exhibit similar pharmacokinetic parameters and bioequivalence to the marketed orodispersible tablet.

In this study, there were a few challenges in quantifying vardenafil in rabbit plasma. The $10 \mathrm{mg}$ dose of vardenafil ODT administered in the rabbit was low; only $150 \mu \mathrm{L}$ of plasma samples were recovered at each time point of blood collection. Most previous studies required a large sample volume to achieve a very low limit of quantification (LLOQ). Carlucci et al. (2009) developed a method to measure vardenafil in human plasma using high-performance liquid chromatography (HPLC) with ultraviolet (UV) detection [10]. However, this method was tedious and involves double extraction steps of organic solvents, also requiring a large amount of plasma $(1 \mathrm{~mL})$ and a high injection volume $(20 \mu \mathrm{L})$ with a running time of $15 \mathrm{~min}$ [10]. A validated HPLC tandem fluorescence detector was used to quantify vardenafil in rat plasma [11]. This method has a relatively long run time of $18 \mathrm{~min}$ and the LLOQ remained high (10 ng/mL) [11]. Abu El-Enin et al. (2015) developed a spectrofluorimetric method to quantify vardenafil in human plasma and pharmaceutical products [12]. Despite the simple protein precipitation method with acetonitrile only, this method requires a large amount of human plasma $(1 \mathrm{~mL})$ to achieve an LLOQ of $10 \mathrm{ng} / \mathrm{mL}$ [12].

Apart from the HPLC with UV detection, liquid chromatography with tandem mass spectrometry (LC/MS/MS) can also be used to quantify drugs and metabolites in biological samples because of its high sensitivity and selectivity. This requires only a small sample volume and has a short analytical time.

A few validated LC/MS/MS methods that quantify vardenafil in plasma have previously been published $[4,13]$. A method developed by $\mathrm{Ku}$ et al. (2009) to measure vardenafil in human plasma requires $0.25 \mathrm{~mL}$ of plasma to achieve an LLOQ of $0.5 \mathrm{ng} / \mathrm{mL}$ [4]. Another method by Lake et al. (2010) requires $0.2 \mathrm{~mL}$ of plasma to achieve an LLOQ of $0.2 \mathrm{ng} / \mathrm{mL}$ [13]. These two methods require liquid-liquid extraction and solvent evaporation in their sample preparation $[4,13]$. By contrast, Bhadoriya et al. (2018) developed a method to extract tadalafil from $0.2 \mathrm{~mL}$ of human plasma via solid-phase extraction [14]. The calibration curve was linear over the concentration range of $0.5-500 \mathrm{ng} / \mathrm{mL}$ [14]. Conversely, Kim et al. (2017) developed a method using acetonitrile to precipitate tadalafil from $0.02 \mathrm{~mL}$ of human plasma [15]. This method had achieved an LLOQ of $5 \mathrm{ng} / \mathrm{mL}$ with a total run time of $1 \mathrm{~min}$ [15]. The aforementioned methods require at least $200 \mu \mathrm{L}$ of plasma associated with tedious extraction methods to achieve LLOQ of $0.5 \mathrm{ng} / \mathrm{mL}$. Thus, a new method is required to address the problem of limited samples and achieve a very low LLOQ.

\section{Materials and Methods}

2.1. Materials and Reagents. Vardenafil hydrochloride trihydrate (USP) was purchased from Medigene (M) Sdn Bhd, Malaysia. The purity of vardenafil hydrochloride trihydrate and tadalafil standard was all $>99 \%$. LCMS-grade acetonitrile and formic acid were also purchased from SigmaAldrich (M) Sdn Bhd. Standard tadalafil was obtained from the Faculty of Pharmacology, University of Malaya. Pooled blank plasma was obtained from the Animal Experimental Unit (AEU) of the University of Malaya.

2.2. Preparation of Standards and Quality Control (QC). A stock solution of vardenafil $(1 \mathrm{mg} / \mathrm{mL})$ and tadalafil as Internal Standard (IS) were prepared in acetonitrile. The stock solution was further diluted with rabbit plasma to make working standard solutions in concentrations of $0.5,1,5,10$, 20, 30, 50, and $60 \mathrm{ng} / \mathrm{mL}$. Internal standards with a final concentration of $40 \mathrm{ng} / \mathrm{mL}$ were prepared. The same method was used to prepare three QC samples at low $(1.5 \mathrm{ng} / \mathrm{mL})$, medium $(25 \mathrm{ng} / \mathrm{mL})$, and high $(45 \mathrm{ng} / \mathrm{mL})$.

2.3. Sample Preparation. A simple protein precipitation method was used to extract vardenafil and IS from plasma samples. First, $100 \mu \mathrm{L}$ of rabbit plasma was combined with $25 \mu \mathrm{L}$ tadalafil (IS) and vortex-mixed for $30 \mathrm{~s}$. Then, $200 \mu \mathrm{L}$ of ice-cold acetonitrile was added to the mixture, and it was vortex-mixed again for $30 \mathrm{~s}$ to precipitate the protein. Subsequently, the mixture was centrifuged at $14000 \mathrm{rpm}$ at $5^{\circ} \mathrm{C}$ for $10 \mathrm{~min}$. The supernatant was collected, and $2 \mu \mathrm{L}$ of aliquot was injected directly into LC/MS/MS.

2.4. Chromatographic Conditions. Chromatographic separation was conducted using Agilent's Zorbax Eclipse Plus $(2.1 \times 50 \mathrm{~mm}$ i.d; $1.8 \mu \mathrm{m})$ coupled with a guard column. Gradient elution was achieved using mobile phases consisting of $0.1 \%(\mathrm{v} / \mathrm{v})$ formic acid in water (solvent $\mathrm{A}$ ) and acetonitrile (100\%, solvent B). Table 1 describes the gradient conditions used in the method. The flow rate of liquid chromatography (LC) was maintained at $0.4 \mathrm{~mL} / \mathrm{min}$, and the total time to run the test was $6 \mathrm{~min}$. The retention time for vardenafil and tadalafil was 1.56 and $1.84 \mathrm{~min}$, respectively.

2.5. Mass Spectrometric Conditions. Mass spectrometry with electrospray ionization set at positive mode was used. The collision energy was set at $45 \mathrm{eV}$, cell accelerator voltage at $4 \mathrm{~V}$, and the fragmentor at $135 \mathrm{~V}$. The gas temperature was set at $280^{\circ} \mathrm{C}$ with the nebulizer at 50 psi and a $12 \mathrm{~L} / \mathrm{min}$ flow rate. The aforementioned settings were determined when the highest signal was shown. The mass transitions of vardenafil were identified as $\mathrm{m} / \mathrm{z} 489 \longrightarrow 151$ as the quantifier and $\mathrm{m} / \mathrm{z}$ $489 \longrightarrow 312$ as the qualifier. Conversely, the mass 
TABle 1: Gradient settings of mobile phase for vardenafil hydrochloride trihydrate assay.

\begin{tabular}{lcc}
\hline & \multicolumn{2}{c}{$\begin{array}{c}\text { Percentage of mobile } \\
\text { phase in eluent }\end{array}$} \\
Time $(\min )$ & A & B \\
\hline 0.0 & 90 & 10 \\
0.5 & 10 & 90 \\
3.0 & 90 & 10 \\
6.0 & 90 & 10 \\
\hline
\end{tabular}

A: $0.1 \%(\mathrm{v} / \mathrm{v})$ formic acid in water; B: acetonitrile.

transitions of tadalafil were identified as $\mathrm{m} / \mathrm{z} 390 \longrightarrow 169$ as the quantifier and $\mathrm{m} / \mathrm{z} 390 \longrightarrow 135$ as the qualifier. Figure 1 shows the mass spectrums of both vardenafil and tadalafil.

2.6. Method Validation. The method was successfully validated to show the accuracy, precision, specificity, linearity, stability, and percentage of recovery from the rabbit plasma. Validation was conducted according to the Bioanalytical Method Validation: Guideline for Industry published by the United States Food and Drug Administration (USFDA) [16]. This method was validated within the concentration range of $0.5-60 \mathrm{ng} / \mathrm{mL}$ with three levels of quality control (QC) samples: QC low $(1.5 \mathrm{ng} / \mathrm{mL})$, QC medium $(25 \mathrm{ng} / \mathrm{mL})$, and QC high (45 ng/mL).

2.7. Animal Ethics. Animal ethics was approved by the University of Malaya Institutional Animal Care and Use Committee (UM IACUC) with Ethics Reference No: 2018190403/PHARM/PS/GKZ. Rabbits were supplied by the AEU, Faculty of Medicine, University of Malaya.

2.8. Preclinical Application. The study was a randomized, single dose, balanced two-period crossover design with a 7day washout period. Rabbits were fasted for $12 \mathrm{~h}$ before the experiment. Rabbits were allowed free access to water only. During the first period, six rabbits received the test formulation (newly optimized vardenafil ODT), while 6 other rabbits received the reference formulation (Staxyn ${ }^{\circledR}$ ODT $10 \mathrm{mg}$ ) according to a randomization schedule. After a 1week washout period, the rabbits were switched to the other formulation accordingly. Before dosing, rabbits were sedated intramuscularly with a low dose of ketamine $(10 \mathrm{mg} / \mathrm{kg})$ and xylazine $(1 \mathrm{mg} / \mathrm{kg})$ to facilitate drug administration. Then, test or reference formulations were placed under the tongue of the rabbits, as shown in Figure 2. The rabbits were then wrapped with a towel to restrain movement before drawing $0.5 \mathrm{~mL}$ blood samples; these were drawn using the direct puncture technique at each time point with a $27 \mathrm{G} \times 1 / 2$ " needle from the marginal ear vein of each rabbit at $0,0.25$, $0.5,1,1.5,2,3,4,6,8,12$, and $24 \mathrm{~h}$ after drug administration. The blood samples were immediately centrifuged at $14000 \mathrm{rpm}$ at $5^{\circ} \mathrm{C}$ for $10 \mathrm{~min}$, and plasma samples were stored at $-20^{\circ} \mathrm{C}$ until further analysis by LC/MS/MS. At the end of the study, rabbits were euthanized and disposed of according to the laboratory protocols.
2.9. Bioequivalence Evaluation. ANOVA was performed on $\mathrm{AUC}_{0-\infty}, \mathrm{AUC0}-t$, and $C_{\text {max }}$, both with and without $\log$ transformation. Bioequivalence statistics were calculated using the Pheonix WinNolin ${ }^{\circledR} 8.1$ software to determine the $90 \%$ confidence interval range. IBM SPSS Statistics 25 software was used to determine the significance value of $T_{\max }$ and $t_{1 / 2}$.

\section{Results}

3.1. Specificity and Selectivity. Six different sources $(n=6)$ of blank rabbit plasma were used to investigate the specificity and selectivity. No interfering peak was observed at the retention time of the analytes. Figure 3(a) shows the chromatograms of blank plasma. Conversely, blank plasma spiked with LLOQ and upper limit of quantification (ULOQ) concentrations of vardenafil and IS are illustrated in Figures 3(b) and 3(c), respectively. At the retention time of vardenafil, there were no interfering peaks observed in the plasma. Figure $3(\mathrm{~d})$ shows the plasma samples $1.5 \mathrm{~h}$ after drug administration. The test proves that the method has high selectivity and specificity.

3.2. Linearity. Eight different concentrations ranging from 0.5 to $60 \mathrm{ng} / \mathrm{mL}$ were used to establish linearity via the least squares linear regression (weighted $1 / \times$ ). The coefficient of determination $\left(R^{2}\right)$ for eight calibrators was 0.99 , and the calibration curve was found to be linear. A lack-of-fit test was conducted to confirm the linearity of the method. Analysis of variance (ANOVA) test showed that the F value was less than the tabulated $F$ value at a $95 \%$ confidence level; hence, the linear regression showed no lack of fit.

The limit of detection of vardenafil was $0.2 \mathrm{ng} / \mathrm{mL}$, whereas the signal-to-noise ratio was 3 . The lowest concentration on the calibration curve was determined as the LLOQ with the accuracy and precision achieved within $\pm 20 \%$. Three replicates at the lowest concentration of the calibration curve over three consecutive days were used to establish the LLOQ. The LLOQ of vardenafil was found to be $0.5 \mathrm{ng} / \mathrm{mL}$, whereas the signal-to-noise ratio was more than 10 .

3.3. Imprecision and Accuracy. Six replicates of LLOQ, ULOQ, and three levels of QC samples were used to determine the accuracy and precision of the method. Initially, the LLOQ, ULOQ, and three QC samples were extracted six times for one batch. Afterward, they were extracted six times in two additional batches. Table 2 shows the results of the intraday and interday tests for imprecision and accuracy. The highest relative standard deviation (RSD) observed was $8.89 \%$. The assay was reproducible, with an intra-assay imprecision ranging from $1.17 \%$ to $9.17 \%$ and interassay imprecision ranging from $1.31 \%$ to $5.86 \%$. The assay exhibited good intra-assay accuracy within $89.3 \%-105.3 \%$ of the expected value, whereas interassay accuracy was within $94 \%-102 \%$ of the expected value. The results shown in Table 2 meet the acceptance criteria; hence, the imprecision and accuracy of the method are adequate. 


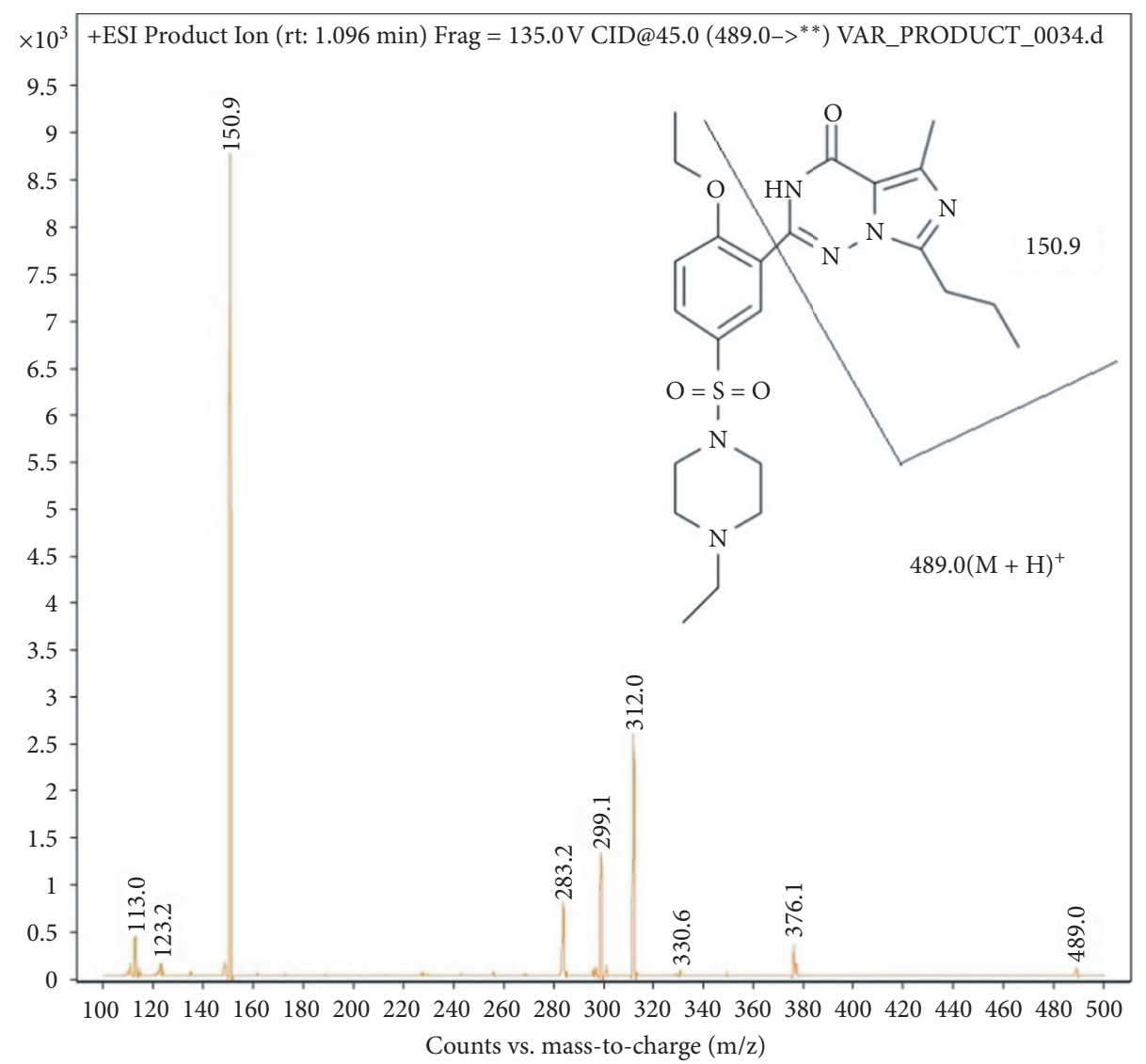

(a)

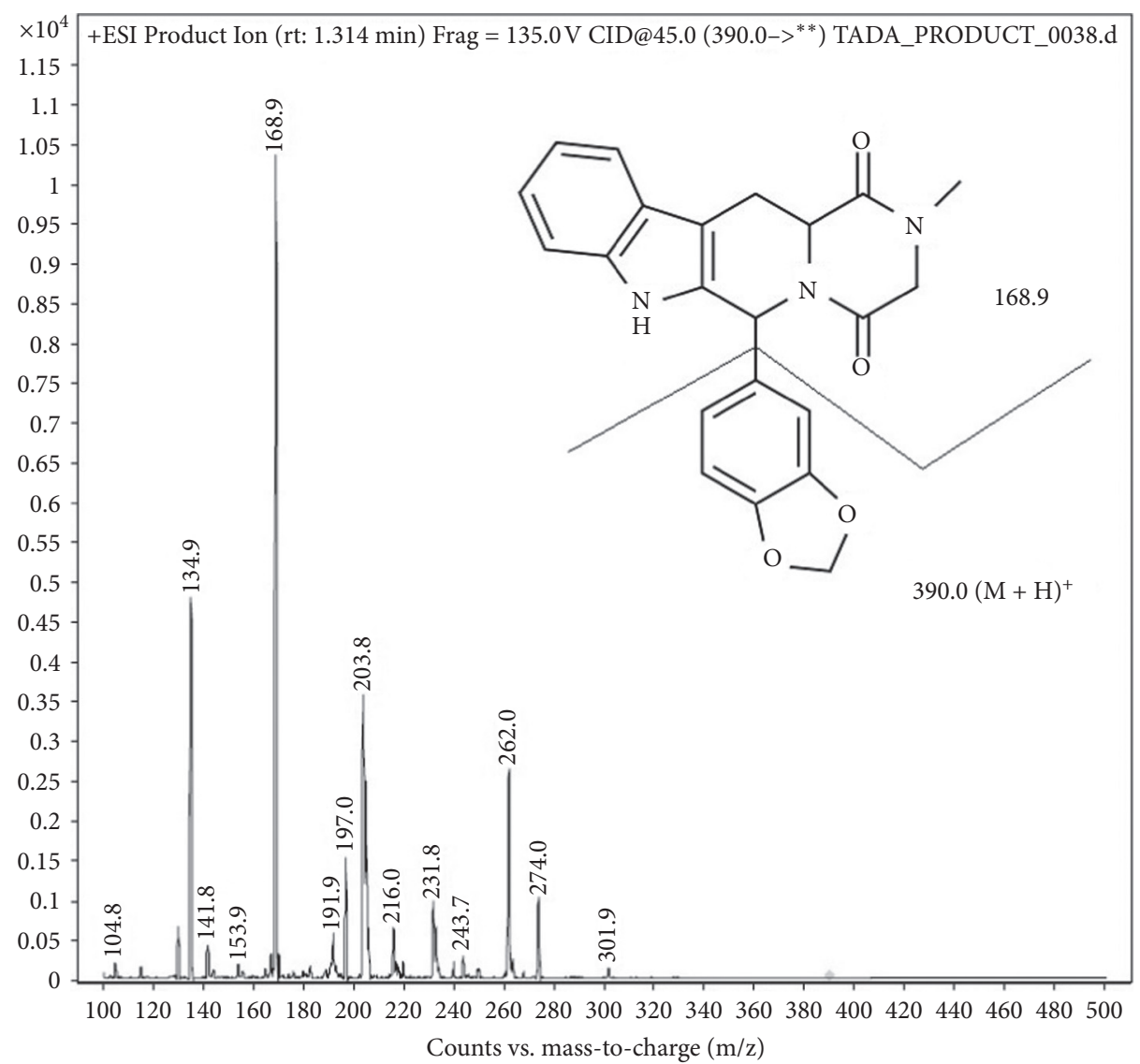

(b)

Figure 1: MS/MS spectrum of product ion for (a) vardenafil and (b) tadalafil in positive ion mode. 


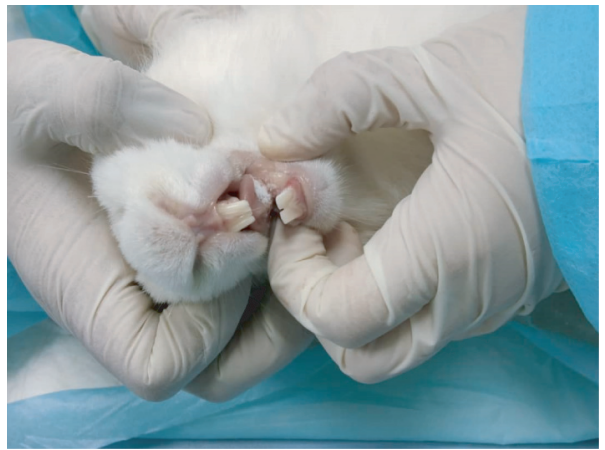

FIGURE 2: Drug administration process and fully disintegrated inside the rabbit mouth under the tongue.

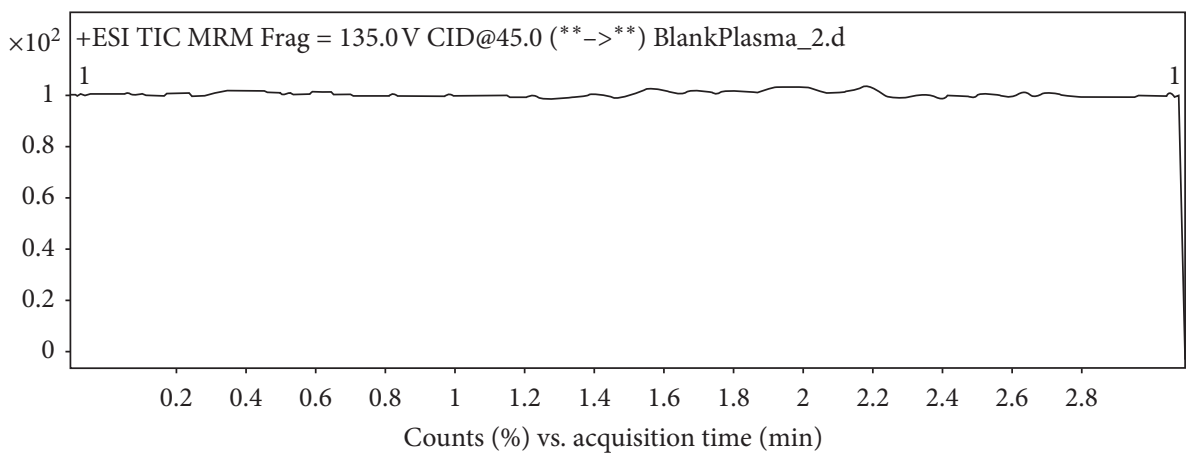

(a)

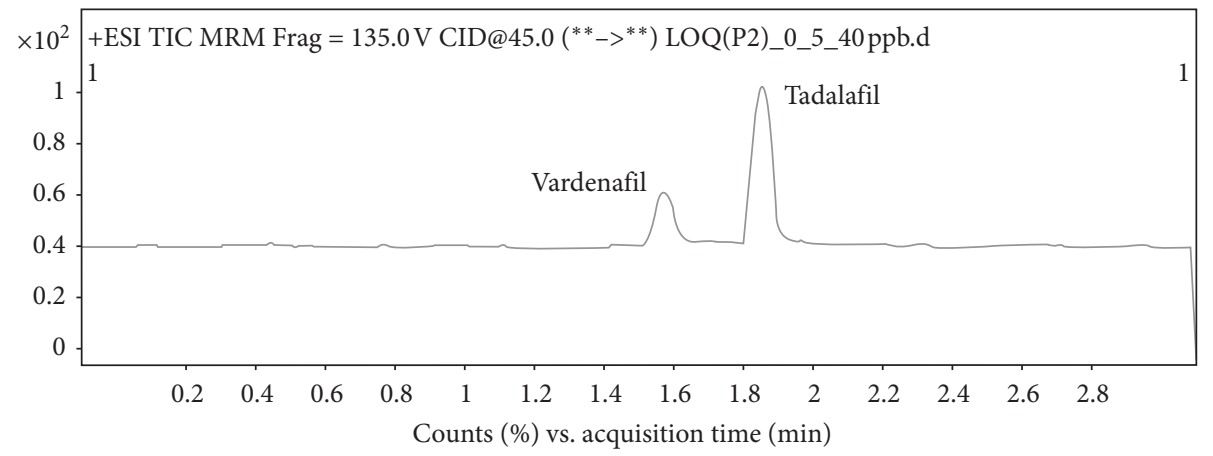

(b)

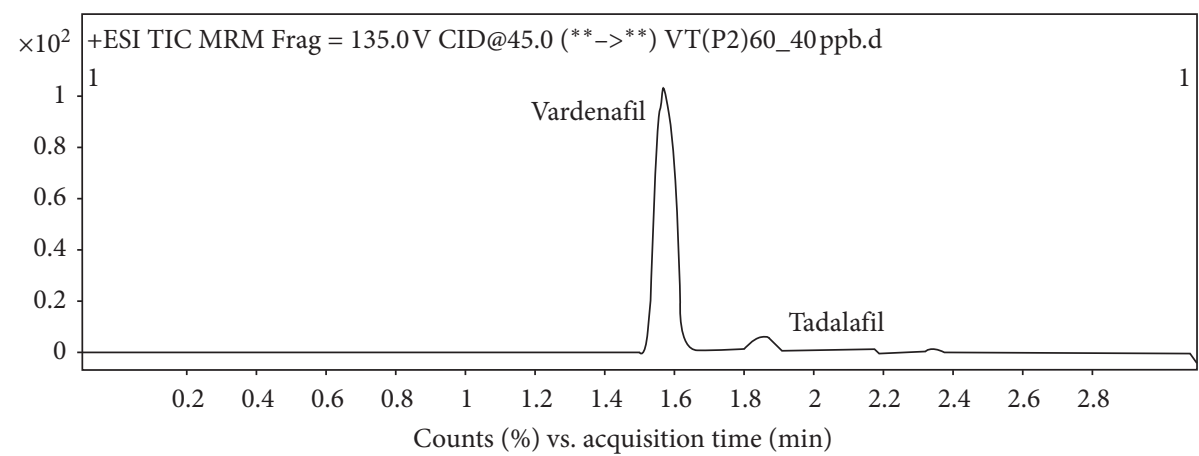

(c)

Figure 3: Continued. 


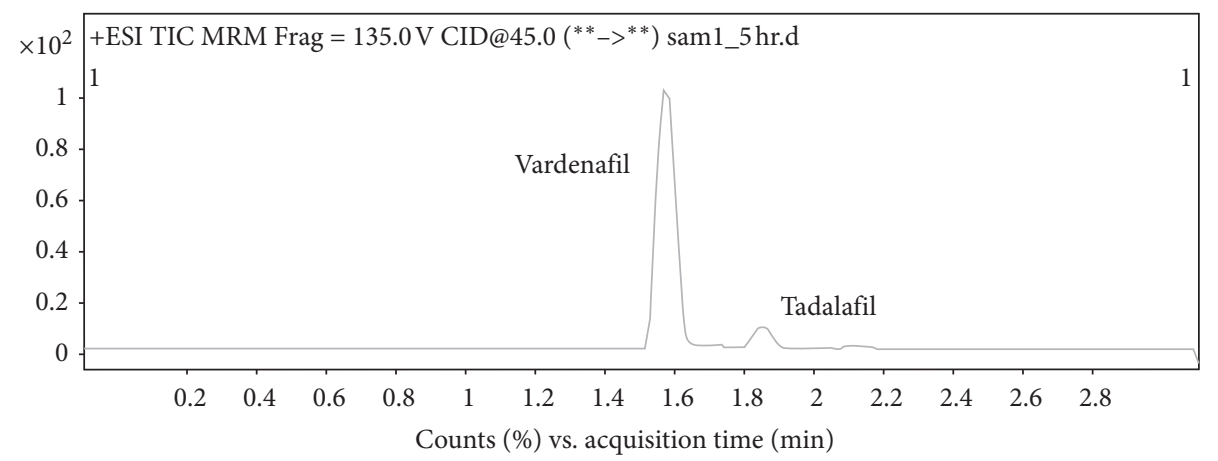

(d)

FIGURE 3: Chromatogram for (a) blank plasma with no interfering peaks at the retention time of the analytes were observed; (b) blank plasma spiked with vardenafil at LLOQ $0.5 \mathrm{ng} / \mathrm{mL}$ and IS at $40 \mathrm{ng} / \mathrm{mL}$; (c) blank plasma spiked with vardenafil at ULOQ $60 \mathrm{ng} / \mathrm{mL}$ and IS at $40 \mathrm{ng} / \mathrm{mL}$; and (d) plasma sample in rabbit $1.5 \mathrm{~h}$ after drug administration with a concentration of $44.95 \mathrm{ng} / \mathrm{mL}$.

TABLE 2: Imprecision and accuracy for the determination of vardenafil in plasma.

\begin{tabular}{|c|c|c|c|c|c|}
\hline & LLOQ $0.5 \mathrm{ng} / \mathrm{mL}$ & LQC $1.5 \mathrm{ng} / \mathrm{mL}$ & MQC $25 \mathrm{ng} / \mathrm{mL}$ & HQC $45 \mathrm{ng} / \mathrm{mL}$ & ULOQ $60 \mathrm{ng} / \mathrm{mL}$ \\
\hline \multicolumn{6}{|c|}{ Intraday $(n=6)$} \\
\hline \multicolumn{6}{|c|}{ Day 1} \\
\hline Mean & 0.46 & 1.48 & 25.77 & 47.36 & 60.16 \\
\hline SD & 0.04 & 2.78 & 9.17 & 7.64 & 4.99 \\
\hline RSD \% & 9.48 & 2.81 & 8.89 & 7.25 & 8.29 \\
\hline Accuracy \% & 92.0 & 98.9 & 103.1 & 105.3 & 100.27 \\
\hline \multicolumn{6}{|l|}{ Day 2} \\
\hline Mean & 0.50 & 1.50 & 25.14 & 46.52 & 61.73 \\
\hline $\mathrm{SD}$ & 0.01 & 1.76 & 2.34 & 1.76 & 1.54 \\
\hline RSD \% & 2.00 & 1.76 & 2.33 & 1.71 & 2.57 \\
\hline Accuracy \% & 100.0 & 100.0 & 100.6 & 103.4 & 100.3 \\
\hline \multicolumn{6}{|l|}{ Day 3} \\
\hline Mean & 0.45 & 1.34 & 25.59 & 44.84 & 60.64 \\
\hline SD & 0.03 & 7.06 & 1.17 & 8.65 & 1.77 \\
\hline RSD \% & 5.88 & 7.90 & 1.14 & 8.68 & 3.01 \\
\hline Accuracy \% & 90.0 & 89.30 & 102.4 & 99.6 & 100.1 \\
\hline \multicolumn{6}{|c|}{ Interday $(n=18)$} \\
\hline Mean & 0.47 & 1.44 & 25.50 & 46.24 & 59.65 \\
\hline SD & 0.03 & 5.86 & 1.31 & 2.86 & 1.93 \\
\hline RSD \% & 0.06 & 6.10 & 1.29 & 2.78 & 3.22 \\
\hline Accuracy \% & 94.0 & 96.1 & 102.0 & 102.8 & 99.41 \\
\hline
\end{tabular}

SD: standard deviation; RSD: relative standard deviation; \%: percentage; LLOQ: lower limit of quantification; LQC: low quality control; MQC: medium quality control; HQC: high quality control; ULOQ: upper limit of quantification; ng indicates nanograms; mL indicates milliliters.

3.4. Stability. Assessment of stability was conducted with three replicates of low (LQC) and high quality control (HQC) for various storage conditions. The stability of vardenafil as shown in Table 3 was tested in plasma at room temperature for $8 \mathrm{~h}$, at $10^{\circ} \mathrm{C}$ in an autosampler for $24 \mathrm{~h}$, at $20^{\circ} \mathrm{C}$ for three freeze-thaw cycles, and at $-20^{\circ} \mathrm{C}$ for 2 months. To meet acceptance criteria, the RSD must be $\leq 15 \%$. In this study, the highest RSD observed was $12.72 \%$, and the mean accuracy was within $88.7 \%-108.4 \%$ with no significant degradation of vardenafil, as presented in Table 3 .

3.5. Recovery. The mean recovery of vardenafil and IS from plasma was determined to be $101.4 \%$ and $70.0 \%$, respectively (Table 4). To investigate the matrix effect, the corresponding peak areas of the postextraction spiked samples were compared with the extraction of samples from mobile phase solution at LQC, MQC, and HQC levels. The acceptance criteria for the matrix effect include an RSD of $\leq 15 \%$. In this study, the highest RSD recorded in Table 5 was $4.38 \%$. Therefore, no significant matrix effect was observed.

3.6. Dilution Integrity. A dilution integrity test was conducted with six replicates of plasma samples diluted from plasma containing $350 \mathrm{ng} / \mathrm{mL}$ of vardenafil with a $1: 10$ dilution factor. The dilution was done with rabbit plasma. In this study, a concentration of $350 \mathrm{ng} / \mathrm{mL}$ was used for dilution because it covers all the detected concentration ranges, and the diluted concentration $(35 \mathrm{ng} / \mathrm{mL})$ does not 
TABLE 3: Stability test of vardenafil in plasma.

\begin{tabular}{|c|c|c|c|}
\hline & & LQC (AUC ratio) & HQC (AUC ratio) \\
\hline \multirow{4}{*}{ Post $8 \mathrm{~h}$ at $25^{\circ} \mathrm{C}$} & Mean & 0.92 & 29.04 \\
\hline & SD & 0.09 & 1.68 \\
\hline & RSD \% & 10.68 & 5.79 \\
\hline & Accuracy \% & 98.2 & 100.1 \\
\hline \multirow{4}{*}{ Post $10 \mathrm{~h}$ at $10^{\circ} \mathrm{C}$} & Mean & 0.85 & 29.92 \\
\hline & $\mathrm{SD}$ & 0.04 & 3.25 \\
\hline & RSD \% & 4.94 & 10.89 \\
\hline & Accuracy \% & 90.5 & 103.1 \\
\hline \multirow{4}{*}{ Three times freeze-thaw at $-20^{\circ} \mathrm{C}$} & Mean & 0.92 & 31.45 \\
\hline & SD & 0.11 & 0.76 \\
\hline & RSD \% & 12.72 & 2.44 \\
\hline & Accuracy \% & 98.1 & 108.4 \\
\hline \multirow{4}{*}{ One-month stability at $-20^{\circ} \mathrm{C}$} & Mean & 0.91 & 29.08 \\
\hline & SD & 0.02 & 0.54 \\
\hline & RSD \% & 2.66 & 1.86 \\
\hline & Accuracy \% & 96.9 & 100.2 \\
\hline \multirow{4}{*}{ Two-month stability at $-20^{\circ} \mathrm{C}$} & Mean & 0.97 & 24.21 \\
\hline & SD & 0.08 & 2.63 \\
\hline & RSD \% & 8.55 & 10.22 \\
\hline & Accuracy \% & 103.4 & 88.7 \\
\hline
\end{tabular}

SD: standard deviation; RSD: relative standard deviation; \%: percentage; LQC: low quality control; HQC: high quality control; $n=3$.

TABLE 4: Recovery for vardenafil (standard) and internal standard.

\begin{tabular}{lcc}
\hline & Standard & Internal standard \\
\hline Recovery \% & & \\
LQC & 99.81 & 74.06 \\
MQC & 103.84 & 67.09 \\
HQC & 100.39 & 68.57 \\
Mean & 101.4 & 70.0 \\
SD & 2.17 & 3.67 \\
RSD \% & 2.14 & 5.25 \\
\hline
\end{tabular}

SD: standard deviation; RSD: relative standard deviation; \%: percentage; LQC: low quality control; MQC: medium quality control; HQC: high quality control; $n=3$.

TABLE 5: Matrix effect of vardenafil in plasma.

\begin{tabular}{lcc}
\hline & LQC (AUC ratio) & HQC (AUC ratio) \\
\hline Mean & 1.22 & 1.30 \\
SD & 0.04 & 1.46 \\
RSD \% & 3.59 & 4.38 \\
\hline
\end{tabular}

SD: standard deviation; RSD: relative standard deviation; \%: percentage; LQC: low quality control; MQC: medium quality control; $n=6$.

overlap with any of the QCs or the calibration points. An RSD of $\leq 15 \%$ is needed to meet acceptance criteria. The mean accuracy and RSD were $94.85 \%$ and $8.35 \%$, respectively (Table 6). This indicates that samples with analytes above the validated range can be diluted into the measurable ranges, as shown in Figure 4.

3.7. Pharmacokinetic Parameter. All pharmacokinetic parameters were calculated using noncompartmental analysis using Phoenix Win Nolin ver.8.0; these are summarized in Table 7. The value of the measured area under the curve from
TABle 6: Dilution integrity test of vardenafil in plasma.

\begin{tabular}{lc}
\hline Expected concentration & $35 \mathrm{ng} / \mathrm{mL}$ \\
\hline Mean \% & 94.85 \\
SD & 7.93 \\
RSD \% & 8.35 \\
\hline
\end{tabular}

SD: standard deviation; RSD: relative standard deviation; \%: percentage; $n=6$.

0 to $24 \mathrm{~h}\left(\mathrm{AUC}_{0-24 t}\right)$ and area under the curve from 0 to infinity $\left(\mathrm{AUC}_{0-\infty}\right)$ for both test and reference formulations were the same, i.e., $174.3 \pm 95.91$ and $176.45 \pm 76.88$, respectively. Conversely, the maximum concentration $\left(C_{\max }\right)$ and time to achieve maximum concentration $\left(T_{\max }\right)$ were $75.36 \pm 59.53 \mathrm{ng} / \mathrm{mL}$ and $1.42 \pm 0.19 \mathrm{~h}$ for the test formulation, whereas these were $58.22 \pm 36.11 \mathrm{ng} / \mathrm{mL}$ and $2.04 \pm 0.33 \mathrm{~h}$ for the reference formulation, respectively. The mean $t_{1 / 2}$ values for the test and reference formulations were 4.83 and $4.75 \mathrm{~h}$, respectively. The mean $\mathrm{AUC}_{0-24 t}$ and $t_{1 / 2}$ for the test and reference formulation were very close to each other. The mean value of $t_{1 / 2}$ was consistent with a previous report [9]. The $C_{\max }$ value for the test formulation was higher than the reference formulation. The $T_{\max }$ value for the test formulation was lower than that for the reference formulation, indicating that the test formulation achieved the maximum therapeutic effect in a shorter amount of time.

\section{Discussion}

4.1. Advantages of the Method. Liquid-liquid extraction requires a drying process to enhance the resolution of the peak, which is time-consuming, requires a large amount of organic solvent, and has inconsistent recovery [17]. Solid-phase extraction is a better option with cleaner extraction compared with liquid-liquid extraction $[14,17]$. However, this 


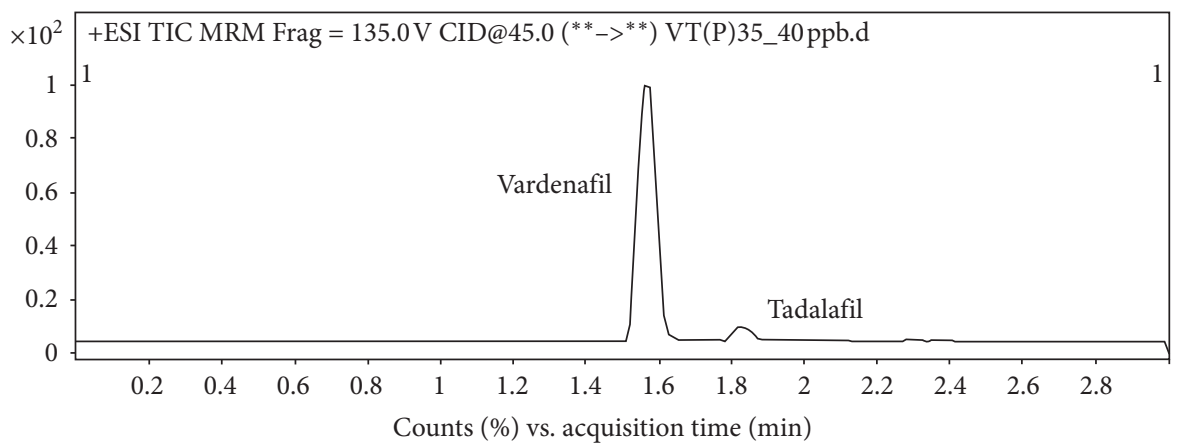

FIgURE 4: Chromatogram for plasma concentration of $35 \mathrm{ng} / \mathrm{mL}$ that diluted within the calibration range.

TABLE 7: Pharmacokinetic parameters of the optimized formulation of vardenafil orodispersible tablet (test) and marketed orodispersible tablet formulation (reference) in New Zealand white rabbit.

\begin{tabular}{|c|c|c|c|c|c|}
\hline & $T_{\max }(\mathrm{h})$ & $C_{\max }(\mathrm{ng} / \mathrm{mL})$ & $\mathrm{AUC}_{0-24 t}(\mathrm{ng} \cdot \mathrm{h} / \mathrm{mL})$ & $\mathrm{AUC}_{0-\infty}(\mathrm{ng} \cdot \mathrm{h} / \mathrm{mL})$ & $t_{1 / 2}(\mathrm{~h})$ \\
\hline \multicolumn{6}{|l|}{ Formulation $T$} \\
\hline$N$ & & & 12 & & \\
\hline Mean & $1.42 \pm 0.19$ & $75.36 \pm 59.53$ & $174.38 \pm 95.91$ & $174.38 \pm 95.91$ & $4.83 \pm 1.63$ \\
\hline Min & 1.00 & 21.74 & 63.22 & 63.22 & 1.43 \\
\hline Median & 1.50 & 72.79 & 163.12 & 163.12 & 5.12 \\
\hline Max & 1.50 & 240.20 & 393.13 & 393.13 & 6.64 \\
\hline $\mathrm{CV} \%$ & 13.74 & 78.99 & 54.99 & 54.99 & 33.85 \\
\hline $\begin{array}{l}\text { Geometric } \\
\text { mean }\end{array}$ & 1.40 & 59.18 & 150.88 & 150.88 & 4.45 \\
\hline \multicolumn{6}{|l|}{ Formulation $R$} \\
\hline$N$ & & & 12 & & \\
\hline Mean & $2.04 \pm 0.33$ & $58.21 \pm 36.11$ & $176.45 \pm 76.88$ & $176.45 \pm 76.88$ & $4.75 \pm 0.85$ \\
\hline Min & 1.50 & 13.15 & 66.47 & 66.47 & 3.42 \\
\hline Median & 2.00 & 46.24 & 171.18 & 171.18 & 4.63 \\
\hline $\operatorname{Max}$ & 3.00 & 140.96 & 295.46 & 295.46 & 5.88 \\
\hline CV\% & 16.37 & 62.03 & 43.57 & 43.57 & 17.99 \\
\hline $\begin{array}{l}\text { Geometric } \\
\text { mean }\end{array}$ & 2.02 & 48.63 & 159.56 & 159.56 & 4.68 \\
\hline
\end{tabular}

$R$ indicates reference; $T$ indicates test; $h$ indicates time in hours; $n g$ indicates nanogram; $m L$ indicates milliliters; $\mathrm{AUC}_{0-\mathrm{t}}$ indicates the measured AUC from 0 to $24 \mathrm{~h} ; \mathrm{AUC}_{0-\infty}$ indicates area under the curve until infinite; $N$ indicates numbers of rabbits; SD indicates standard deviation; CV indicates coefficient variation; $T_{\max }$ indicates time to reach the maximum peak; $C_{\max }$ indicates the maximum concentration that achieved; $t_{1 / 2}$ indicates the half-life of the drug.

method requires conditioning of the column and is expensive. Comparatively, simple protein precipitation with ice-cold acetonitrile has been used in this study to extract vardenafil. This extraction method is simple, less costly, and time-saving compared with previously published methods.

This newly developed LC/MS/MS method also has high sensitivity, as it requires only a small amount $(100 \mu \mathrm{L})$ of plasma and a small injection volume $(2 \mu \mathrm{L})$ compared with the previous method. Despite the small amount of sample and injection volume, this method still can achieve a low quantification level of drug concentration (LLOQ $=0.5 \mathrm{ng}$ / $\mathrm{mL}$ ). Sample analysis can be conducted rapidly with a total running time of $6 \mathrm{~min}$. Chromatographic separation was found to have better separation with gradient elution compared to isocratic elution. After $1 \mathrm{~min}$ of initiation, vardenafil and IS were separated with retention times of 1.56 and $1.84 \mathrm{~min}$, respectively.
In this study, the intra- and interassay imprecision was RSD $\leq 20 \%$ for LQC and RSD $\leq 15 \%$ for MQC and HQC. The method exhibited good intra-assay accuracy within $89.3 \%-105.3 \%$ of the expected value and an interassay accuracy within $94 \%-102 \%$ of the expected value. Thus, this method exhibited acceptable precision and accuracy. The stability study of vardenafil shows that vardenafil was stable at room temperature for $8 \mathrm{~h}$, at $10^{\circ} \mathrm{C}$ in an autosampler for $24 \mathrm{~h}$, at $20^{\circ} \mathrm{C}$ for three freeze-thaw cycles, and at $-20^{\circ} \mathrm{C}$ for 2 months.

4.2. Rabbit Model. The use of rabbits as models for sublingual delivery investigation has been widely established and reported in the literature. Similar to rabbits, other animals such as dogs, pigs, and monkeys are acceptable models and have nonkeratinized oral mucosa with 


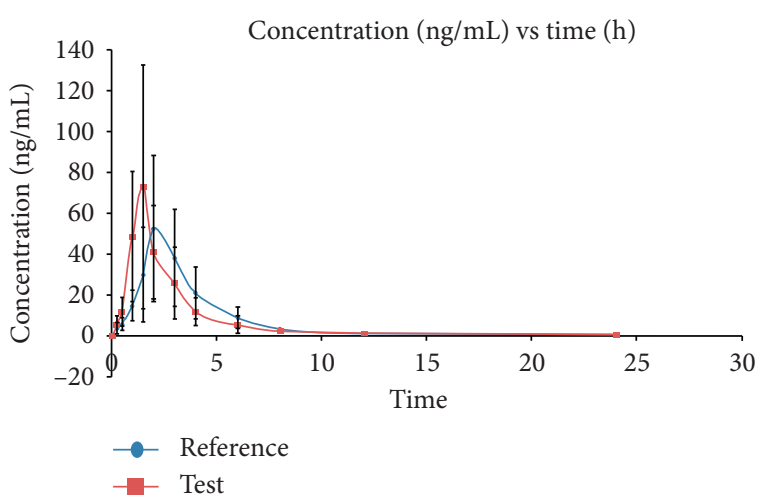

Figure 5: Mean plasma concentrations (ng/mL) versus time (h) of optimized formulation of vardenafil orodispersible tablet (test) and marketed orodispersible tablet formulation in New Zealand white rabbit (value expressed as mean $\pm \mathrm{SD}$ with $n=12$ )

permeability values similar to those of humans [18]. Rabbits and dogs are generally accepted as the most suitable animal models for humans because of the histological similarities in their oral cavities [19], whereas the ease of handling and animal cost makes rabbits more favorable over dogs [20]. Rabbit and human sublingual mucosa are both nonkeratinized; hence, sublingual drug delivery in rabbits can be correlated to intraoral absorption in humans [20].

4.3. Application of the Method. This newly developed and validated LC/MS/MS method was successfully applied in a pharmacokinetics study of the newly optimized formulation of vardenafil orodispersible tablet (test formulation) compared with the marketed orodispersible tablet (reference formulation) in 12 healthy rabbits. Figure 5 plots the mean plasma concentration versus time profile for vardenafil in 12 rabbits. The test formulation was able to reach maximum concentration in the body faster than the reference formulation and has a faster onset of action. The percentages of extrapolation as shown in Figure 5 were 3.14\% and 2.58\% for the test and reference formulations, respectively. Low percentages of extrapolation indicate a good sampling point. Additionally, the very low LLOQ achieved in this method enabled the graph to be plotted properly.

\subsection{ANOVA and Bioequivalence Statistics}

4.4.1. Area under the Curve, $\mathrm{AUC}_{0-24 t}$. The $90 \%$ confidence interval (CI) for the test/reference ratio was 78.11-114.46. However, the test formulation was not bioequivalent to the reference formulation in terms of AUC because the result is not within the acceptable range of $90 \% \mathrm{CI}$ of $80 \%-125 \%$ for Log 10 AUC. The acceptable range was according to the European Community's-The European Agency for the Evaluation of Medicinal Products (EC-EMEA), USFDA, and the National Pharmaceutical Regulatory Agency of Malaysia (NPRA). The Anderson Hauck probability of the result falling outside $80 \%-125 \%$, which indicates the probability of a value outside $80 \%-125 \%$ is 0.059 (5.9 in 100). This value is larger than 0.05 (5 in 100), the level of significance, and hence, the above hypothesis cannot be rejected. Although test formulation is not bioequivalent to the reference formulation, their mean $\mathrm{AUC}_{0-24 \mathrm{t}}$ values were very close (174.38 and $176.45 \mathrm{ng} \cdot \mathrm{h} / \mathrm{mL}$, respectively).

4.4.2. Maximum Concentration, $C_{\max }$. The $90 \%$ CI for the test/reference ratio was $89.56-165.35$. The test formulation was not bioequivalent to the reference formulation in terms of $C_{\max }$ because the result did not fall within the acceptable range of $90 \%$ CI of $80 \%-125 \%$ for Log 10 AUC. The acceptable range was according to the EC-EMEA, USFDA, and NPRA. The Anderson Hauck probability of the result falling outside $80 \%-125 \%$, which indicates the probability of a value outside $80 \%-125 \%$, is 0.42 (42 in 100). This value is larger than $0.05(5$ in 100), the level of significance, and hence, the above hypothesis cannot be rejected. Although the test formulation is not bioequivalent to the reference formulation, the mean $C_{\max }$ for the test formulation was higher than the reference formulation (75.36 and $58.22 \mathrm{ng} / \mathrm{mL}$, respectively).

4.4.3. Time to Reach Maximum Concentration, $T_{\max }$. The mean $T_{\max }$ value for vardenafil was 1.42 and $2.04 \mathrm{~h}$ for the test and reference formulations, respectively. Wilcoxon signed-rank test showed a statistically significant difference in terms of $T_{\max }$ values $(p<0.05)$ between the two. This means that the test formulation reaches its maximum concentration faster than the reference formulation. Hence, the test formulation is better than the reference formulation.

4.4.4. Half-Life, $t_{1 / 2}$. The mean $t_{1 / 2}$ values for vardenafil were 4.83 and $4.75 \mathrm{~h}$ for the test and reference formulations, respectively. Paired $t$-test showed no statistically significant difference in terms of $t_{1 / 2}$ values between the two $(p>0.05)$.

The above results prove that our newly optimized formulation achieved almost equal bioavailability to the test formulation and even achieved higher maximum concentration at a faster rate compared with the reference formulation. No significant differences were observed in $t_{1 / 2}$ for both test and reference formulations.

\section{Conclusion}

We report on the development and validation of a simple, rapid, sensitive, and specific LC/MS/MS method for the determination of vardenafil in rabbit plasma. The major advantage of using the MS/MS system is its specificity in targeting ions of interest. This method was applied successfully to the pharmacokinetic study of vardenafil in healthy rabbits after a single dose of $10 \mathrm{mg}$ vardenafil orodispersible tablet. The newly optimized vardenafil orodispersible tablet formulation exhibited similar pharmacokinetic data in terms of $\mathrm{AUC}_{0-24 t}$ and $t_{1 / 2}$. It also achieved almost equal bioavailability, higher maximum concentration, and shorter time to reach the maximum concentration 
compared to the reference formulation. The objective of developing a new quantification method to solve the challenges in this study was achieved.

\section{Data Availability}

The data used to support the finding of this study are included within the article.

\section{Conflicts of Interest}

The authors declare no conflicts of interest regarding the publication of this paper.

\section{Authors' Contributions}

The authors declare that the work was done by the authors named in this article and that the authors will be responsible for any liabilities pertaining to claims relating to the content of this article. Conceptualization was carried out by Riyanto Teguh Widodo, Zamri Chik, and Teh Lay Kek. Methodology was performed by Gan Kok Zheng, Zamri Chik, and Teh Lay Kek. Software was provided by Mohd Salleh Rofiee and Mohd Izwan Mohamad Yusof. Validation and analysis were conducted by Gan Kok Zheng and Mohd Izwan Mohamad Yusof. Investigation was performed by Gan Kok Zheng, Mohd Salleh Rofiee, and Mohd Izwan Mohamad Yusof. Data were collected by Gan Kok Zheng. The manuscript was written by Gan Kok Zheng. The manuscript was reviewed by Riyanto Teguh Widodo, Zamri Chik, and Teh Lay Kek. The study was supervised by Riyanto Teguh Widodo, Zamri Chik, and Teh Lay Kek.

\section{Acknowledgments}

The authors acknowledge iPROMISE, UiTM, for their assistance and for lending the facilities and equipment to complete the analysis.

\section{References}

[1] J. Hui, S. He, R. Liu, Q. Zeng, H. Zhang, and A. Wei, "Trends in erectile dysfunction research from 2008 to 2018: a bibliometric analysis," International Journal of Impotence Research, vol. 32, no. 4, pp. 409-419, 2020.

[2] G. M. Keating and L. J. Scott, "Vardenafil," Drugs, vol. 63, no. 23, pp. 2673-2703, 2003.

[3] R. A. Kloner, "Cardiovascular effects of the 3 phosphodiesterase-5 inhibitors approved for the treatment of erectile dysfunction," Circulation, vol. 110, no. 19, pp. 3149-3155, 2004.

[4] H. Y. Ku, J. H. Shon, K. H. Liu, J. G. Shin, and S. K. Bae, "Liquid chromatography/tandem mass spectrometry method for the simultaneous determination of vardenafil and its major metabolite, $\mathrm{N}$-desethylvardenafil, in human plasma: application to a pharmacokinetic study," Journal of Chromatography B: Analytical Technologies in the Biomedical and Life Sciences, vol. 877, no. 1-2, pp. 95-100, 2009.

[5] A. Zucchi, E. Costantini, F. I. Scroppo et al., "The first-generation phosphodiesterase 5 inhibitors and their pharmacokinetic issue," Andrology, vol. 7, no. 6, pp. 804-817, 2019.

[6] P. Hannan, J. Khan, A. Khan, and S. Safiullah, "Oral dispersible system: a new approach in drug delivery system,"
Indian Journal of Pharmaceutical Sciences, vol. 78, no. 1, pp. 2-7, 2016.

[7] M. Sanford, "Vardenafil orodispersible tablet," Drugs, vol. 72, no. 1, pp. 87-98, 2012.

[8] H. Sperling, M. Gittelman, C. Norenberg, E. Ulbrich, and S. Ewald, "Efficacy and safety of an orodispersible vardenafil formulation for the treatment of erectile dysfunction in elderly men and those with underlying conditions: an integrated analysis of two pivotal trials," The Journal of Sexual Medicine, vol. 8, no. 1, pp. 261-271, 2011.

[9] R. Heinig, B. Weimann, H. Dietrich, and M.-F. Böttcher, "Pharmacokinetics of a new orodispersible tablet formulation of vardenafil," Journal of Men's Health, vol. 7, no. 3, p. 325, 2010.

[10] G. Carlucci, P. Palumbo, P. Iuliani, and G. Palumbo, "Development of a method for the determination of vardenafil in human plasma by high performance liquid chromatography with UV detection," Biomedical Chromatography, vol. 23, no. 7, pp. 759-763, 2009.

[11] C. L. Cheng, G. J. Kang, and C. H. Chou, "Development and validation of a high-performance liquid chromatographic method using fluorescence detection for the determination of vardenafil in small volumes of rat plasma and bile," Journal of Chromatography A, vol. 1154, no. 1-2, pp. 222-229, 2007.

[12] M. A. B. Abu El-Enin, M. E.-S. A. Al-Ghaffar Hammouda, D. T. El-Sherbiny, D. R. El-Wasseef, and S. M. El-Ashry, "Validated spectrofluorimetric method for determination of two phosphodiesterase inhibitors tadalafil and vardenafil in pharmaceutical preparations and spiked human plasma," Luminescence, vol. 31, no. 1, pp. 173-178, 2016.

[13] S. T. Lake, P. M. Altman, J. Vaisman, and R. S. Addison, "Validated LC-MS/MS assay for the quantitative determination of vardenafil in human plasma and its application to a pharmacokinetic study," Biomedical Chromatography: BMC, vol. 24, no. 8, pp. 846-851, 2010.

[14] A. Bhadoriya, B. Dasandi, D. Parmar, P. A. Shah, and P. S. Shrivastav, "Quantitation of tadalafil in human plasma using a sensitive and rapid LC-MS/MS method for a bioequivalence study," Journal of Pharmaceutical Analysis, vol. 8, no. 4, pp. 271-276, 2018.

[15] K.-Y. Kim, M. Nam, H.-J. Kwon et al., "Validated UPLC-MS/ MS method for the determination of tadalafil in human plasma and its application to a pharmacokinetic study," Translational and Clinical Pharmacology, vol. 25, no. 1, pp. 21-27, 2017.

[16] U.S.FDA, Bioanalytical Method Validation Guidance for Industry, U.S.FDA, Silver Spring, MD, USA, 2018, https://www. fda.gov/regulatory-information/search-fda-guidancedocuments/bioanalytical-method-validation-guidanceindustry.

[17] V. Anjana, P. Ashok, P. Ajay, V. Amit, and P. Nilesh, "Sample preparation in bioanalysis a review," International Journal of Scientific and Technology Research, vol. 4, no. 8, pp. 6-10, 2015.

[18] I. A. Siegel, K. T. Izutsu, and E. Watson, "Mechanisms of nonelectrolyte penetration across dog and rabbit oral mucosa in vitro," Archives of Oral Biology, vol. 26, no. 5, pp. 357-361, 1981.

[19] S. S. M. Rathbone and I. Pather, "Oral mucosal drug delivery and therapy," in Advances in Delivery Science and TechnologySpringer US, New York, NY, USA, 2015.

[20] M. M. Dali, P. A. Moench, N. R. Mathias, P. I. Stetsko, C. L. Heran, and R. L. Smith, "A rabbit model for sublingual drug delivery: comparison with human pharmacokinetic studies of propranolol, verapamil and captopril," Journal of Pharmaceutical Sciences, vol. 95, no. 1, pp. 37-44, 2006. 